\section{Andamios Revista de Investipación Social}

Andamios. Revista de Investigación Social ISSN: 1870-0063

revistaandamios@uacm.edu.mx

Universidad Autónoma de la Ciudad de México México

Ruiz Nápoles, Pablo

Una visión sobre las facetas políticas del neoliberalismo económico en México

Andamios. Revista de Investigación Social, vol. 9, núm. 19, mayo-agosto, 2012, pp. 393-396

Universidad Autónoma de la Ciudad de México

Distrito Federal, México

Disponible en: http://www.redalyc.org/articulo.oa?id=62824428017

Cómo citar el artículo

Número completo

- Más información del artículo

- Página de la revista en redalyc.org

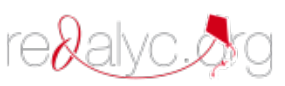

Sistema de Información Científica

Red de Revistas Científicas de América Latina, el Caribe, España y Portugal

Proyecto académico sin fines de lucro, desarrollado bajo la iniciativa de acceso abierto 


\title{
UNA VISIÓN SOBRE LAS FACETAS POLÍTICAS DEL NEOLIBERALISMO ECONÓMICO EN MÉXICO
}

\section{Pablo Ruiz Nápoles*}

\begin{abstract}
Sandoval Ballesteros, Irma Eréndira (2011), Crisis, rentismo e intervencionismo neoliberal en la Banca: México (1982-1999), México: Centro de Estudios Espinoza Yglesias.
\end{abstract}

Crisis, rentismo e intervencionismo neoliberal en la Banca: México (19821999) es una obra de reciente aparición que fue ganadora del primer lugar del premio "Manuel Espinosa Yglesias: Reflexión Política, Económica y Social" en 2009. Se trata, según se desprende de la introducción, de una adaptación de la tesis de doctorado en Ciencia Política de la propia autora en la Universidad de California en Santa Cruz, en los Estados Unidos. Es, por tanto, un trabajo cuidadosamente revisado y dictaminado antes de su publicación, lo que significa que es una obra cuyas hipótesis y metodología de investigación han sido avaladas por expertos, y por lo tanto está en lo fundamental bien documentada, desde la perspectiva de análisis de la Ciencia Política. La obra se estructura en cinco capítulos, el primero corresponde al planteamiento teórico principal y a la exposición de la metodología a seguir, y los tres siguientes a tres coyunturas político-económicas consideradas en el estudio como principales: la nacionalización, privatización y el rescate bancario; y un quinto capítulo se dedica a una comparación internacional y a las conclusiones. Aunque la obra abunda en referencias históricopolíticas no es un trabajo narrativo sino más bien de carácter analítico.

El tema central del estudio consiste en tomar un caso particular, la banca comercial de México en el período 1982-1999, para probar una tesis central más general sobre el neoliberalismo mexicano: la conceptualización de éste como "un proyecto político con

\footnotetext{
* Profesor del Posgrado de la Facultad de Economía de la UNAM. Dirección electrónica: ruizna@servidor.unam.mx
} 
consecuencias económicas" en oposición a la aparentemente más común conceptualización del mismo como "un proyecto económico de consecuencias políticas" (p. 5 y p. 259).

La periodización del estudio corresponde a tres momentos de crisis económico-financieras y/o políticas: la de 1981-82, que dio lugar entre otras cosas a la nacionalización de la banca comercial en septiembre de 1982; la crisis económico-política de 1988, que posibilitó la reprivatización de la banca en 1991-92, y la crisis de divisas de 199495, que dio lugar al salvamento de la banca comercial (prácticamente en quiebra) por parte del Estado con fondos públicos y su ulterior venta al capital bancario extranjero en su casi totalidad. La autora bautiza estos tres momentos del desarrollo de la banca comercial en México como: "Nacionalización neoliberal", "Privatización protegida" y "Nacionalización privatizadora". Así precisamente se titulan los capítulos dos, tres y cuatro, donde respectivamente se analizan a profundidad cada uno de estos momentos.

A lo largo de esta periodización, Sandoval Ballesteros propone tres hipótesis centrales: 1) "la corrupción y el rentismo varían más en función del nivel de incertidumbre política por el que transite un determinado régimen, que por la naturaleza misma del régimen político"; 2) "el neoliberalismo en México no ha implicado la fría imposición de ideas y modelos económicos, sino el hábil manejo de intereses políticos con objeto de dar sustento a nuevas coaliciones redistributivas"; y 3) "el arribo de la democracia y el pluralismo no garantiza de forma automática un manejo limpio y transparente de las respuestas gubernamentales a las crisis políticas o económicas".

Resumir en forma adecuada el trabajo me parece una tarea con poca probabilidad de éxito para un no experto en Ciencia Política como es mi caso. Me propongo, en cambio, destacar lo que desde la perspectiva de un economista se pueden considerar sus mayores aciertos y plantear algunas cuestiones que quizá parezcan debilidades, desde esta misma perspectiva.

El trabajo, visto en su conjunto, constituye un importante esfuerzo por ilustrar en el devenir económico y político, a lo largo de estas dos décadas, el fracaso de las "reformas económicas" vinculadas al llamado Consenso de Washington, en un sector institucional de la importancia 
de la banca comercial. Fracaso que desde luego comprendió no sólo a aquellas reformas orientadas al sector bancario, sino a otros sectores económicos tanto productivos como institucionales y que se tradujo principalmente en la falta de crecimiento económico y en el consecuente aumento del desempleo abierto y disfrazado, así como en el detonar de la migración de trabajadores mexicanos a los Estados Unidos. El enfoque adoptado por Irma Sandoval, la lleva a concentrarse en la arista política del asunto, lo cual logra muy bien, y, desde esta perspectiva, consigue probar todas y cada una de sus hipótesis de trabajo presentadas desde el principio. En este sentido, el libro constituye una visión fresca e innovadora respecto a lo que hemos venido recibiendo y leyendo de analistas políticos con relación a las reformas económicas y políticas neoliberales, quienes usualmente justifican el mal comportamiento de la economía mexicana sobre la base de la insuficiencia en la aplicación de las "reformas económicas", ya en términos cuantitativos, porque harían falta más reformas, o ya en términos cualitativos, porque habría que profundizar en las mismas, lo que deja fuera del análisis no sólo deficiencias económicas de primer orden, sino las carencias políticas de estas reformas que distan mucho de ser democráticas y transparentes y en cambio están plagadas de autoritarismo y corrupción.

Un problema del trabajo es quizá que no basta con probar las tres hipótesis explícitas arriba mencionadas, sino que también habría que probar o al menos validar las paradójicas conceptualizaciones que dan nombre a los capítulos dos, tres y cuatro. En otras palabras, las formulaciones de "Nacionalización neoliberal", "Privatización protegida" y "Nacionalización privatizadora" no son en sí mismas incorrectas o inválidas, pero tendrían que estar más robustamente respaldadas o justificadas. Ello es particularmente el caso de la conceptualización de la "nacionalización neoliberal" de 1982. Este calificativo nos lleva a la necesidad de definir primero qué se entiende en política y en economía por "liberal" y "neoliberal", y sus respectivos conceptos opuestos "conservadurismo" e "intervencionismo estatal". Una rápida revisión a estos conceptos en los Estados Unidos y en México nos aclara que es posible la coexistencia de un gobierno conservador con una política económica neoliberal (por ejemplo, en el caso de Reagan en los Estados Unidos). En tanto que es posible un gobierno liberal con 
una política económica intervencionista o keynesiana (como fue el de Roosevelt en los Estados Unidos). Otra cuestión que hay que tomar en cuenta, sobre todo en el caso de México, es que aun dentro de un Estado intervencionista, como lo fue el México de los gobiernos de Echeverría y López Portillo, en el país coexistieron y de hecho crecieron grupos de tecnócratas neoliberales que sólo esperaban el momento político para accionar libremente las recetas de política económica aprendidas en Harvard, el Instituto Tecnológico Autónomo de Massachusetts y la Universidad de Chicago. El libro se enriquecería mucho al precisar estos aspectos y le permitiría calificar la política económica neoliberal de manera más adecuada. Un segundo problema no menor es que las "reformas económicas" no sólo dieron al traste con las instituciones que el Estado creó para el desarrollo del país, sino que a la fecha el crédito de la banca hacia las actividades económicas es muy menor de lo que solía ser en el período desarrollista, y sobre todo en relación con lo que se otorga a nivel internacional, y de esto parece haber muy poco en el estudio.

Nada de ello, sin embargo, desmerece el trabajo de la doctora Sandoval Ballesteros, que constituye una obra muy interesante de interpretación política sobre la evolución de un sector fundamental para el desarrollo del país en una etapa en la que el pensamiento económico neoliberal ha predominado en México y en el mundo, sin ser capaz de cumplir ninguna de sus promesas de mejoría ni política, ni económica. Considero la lectura de esta obra como indispensable en el estudio del México de la postmodernidad. 